\title{
Desempenho produtivo de cabras submetidas à estação de monta e a duas proporções reprodutor-matrizes
}

\author{
Aurino A. Simplício¹, Marciane da S. Maia¹ \& Eduardo C. D. Muniz¹ \\ 1 Empresa de Pesquisa Agropecuária do Rio Grande do Norte S/A; Avenida da COOPHAB/ Eliza Branco Pereira dos Santos, s/n, Parque das Nações, CEP 59158-160, \\ Parnamirim-RN, Brasil. Caixa Postal 188. E-mail: aa.simplicio@uol.com.br; marcianemaia@yahoo.com.br; edu_muniz@ymail.com
}

\section{RESUMO}

Avaliou-se o efeito da proporção entre reprodutor e matrizes em caprinos Canindé em regime de monta livre no cabril, mantidos na caatinga e suplementados com mistura múltipla sobre parâmetros reprodutivos e o padrão de crescimento das crias, do nascer ao desmame. Os dados foram submetidos à ANOVA e as médias comparadas pelo teste de Tukey a 5,0\% de significância. A fertilidade média das fêmeas ao diagnóstico por ultrassonografia $(94,05 \%)$ e ao parto $(85,71 \%)$ não diferiu entre os tratamentos T0 e TI $(P>0,05)$. $O$ escore da condição corporal das matrizes ao início da estação de monta afetou a fertilidade avaliada por ultrassonografia; o tipo de nascimento influenciou o peso das crias do nascer aos 84 dias mas o sexo influenciou o peso apenas aos 28 dias de idade enquanto o uso de mistura múltipla foi compatível com a fertilidade elevada.

Palavras-chave: caprinos, condição corporal, desenvolvimento ponderal, fertilidade

\section{Reproductive performance of goats submitted to breeding season and two male to female ratio under free mount regime}

\begin{abstract}
This study aimed to evaluate the effect of two ratios of male to females in Canindé goats under free mount regime kept on 'caatinga' and supplemented with multiple mixture on the reproductive performance and the growth pattern of offspring from birth until weaning. The data were submitted to ANOVA and means compared by Tukey test at $5.0 \%$ level of significance. The mean fertility of goats by ultrasound (94.05\%) and parturition (85.71\%) did not show difference between treatment T0 and TI ( $P>0.05)$. The body condition of the goats before the onset of breeding season influenced the fertility evaluated by ultrasound; the type of birth influenced the weight at birth until weaning at 84 days, but sex just affected the weight at 28 days when males were with more weight than females while the use of multiple mixture was compatible with high fertility.
\end{abstract}

Key words: goats, body condition, growth development, fertility 


\section{Introdução}

O desempenho produtivo dos caprinos, independente da função explorada e da fase da exploração, é resultante do genótipo, da sua adaptação ao ambiente, do bem-estar animal, do regime de manejo em uso e dos manejos alimentar, da nutrição, da promoção da saúde e reprodutivo (Soares Filho et al., 2001). Ressalte-se a importância da fertilidade ao parto, da prolificidade e da sobrevivência, particularmente das crias no transcorrer do período de amamentação e na fase de recria (Medeiros et al., 2006; Sarmento et al., 2010). Entende-se que o desenvolvimento de crias caprinas durante o período de amamentação, particularmente no transcorrer do primeiro mês de vida, é estreitamente relacionado com a produção de leite da cabra. Em geral, as cabras nativas apresentam baixa produção de leite e no primeiro mês de vida o consumo de alimentos sólidos é quase insignificante. Assim, para compensar o déficit nutricional propiciado pela reduzida ingestão de leite, torna-se conveniente a inclusão de forragem e concentrado de boa qualidade na dieta das crias, o mais cedo possível. Amaral et al. (2007) registraram, usando crias da raça Saanen submetidas a aleitamento e recebendo ração completa na forma farelada, peletizada e extrusada a partir do $15^{\circ}$ dia de idade, que aos 30 dias o rúmem já estava morfologicamente desenvolvido possibilitando o desaleitamento e o uso de ração completa, peletizada, a partir desta idade. Em crias da raça Canindé, Maia \& Costa (1997) descrevem que a restrição de mamadas associadas à suplementação proteica e energética durante o período de amamentação, favorece o desenvolvimento corporal em comparação com a amamentação ad libitum.

Ao se estabelecer a proporção de reprodutor por matrizes, deve-se dar especial atenção ao regime de manejo; à condição de higidez dos animais; à qualidade do ejaculado; à maturidade e à experiência sexual dos indivíduos de ambos os sexos e ao escore de sua condição corporal ao início da estação de monta (EM) (Mellado et al., 1994, 1996; Simplício \& Ximenes, 2010). Por outro lado, na espécie bovina, resultados de pesquisas sinalizam que elevados níveis de proteína bruta e de proteína degradável no rúmen na dieta influenciam negativamente o desempenho reprodutivo, em virtude de reduzir o $\mathrm{pH}$ na cavidade uterina e a fertilidade e aumentar o período de serviço e o número de serviços por concepção (Jordan \& Swanson, 1979; Canfield et al., 1990; Elrod \& Butler, 1993; Elrod et al., 1993). Por outro lado, o fornecimento de ureia na dieta para fêmeas ovinas foi vinculado ao aumento de ureia e da amônia no fluido das trompas e do útero (McEvoy et al., 1997) e afetou negativamente a qualidade de oócitos e a viabilidade de embriões, a sobrevivência e o seu desenvolvimento após transferência (Fahey et al., 2001; Papadopoulos et al., 2001).

O presente trabalho teve como objetivo avaliar o efeito da proporção reprodutor matrizes em monta livre, pelo período aproximado de $14 \mathrm{~h}$, sobre parâmetros reprodutivos de fêmeas caprinas Canindé suplementadas com mistura múltipla na quantidade máxima de $2 \mathrm{~g} \mathrm{~kg}^{-1}$ de peso vivo a partir de 24 dias pré-estação de monta tal como também o comportamento do peso das crias, do nascimento ao desmame, considerando o tipo de nascimento e o sexo.

\section{Material e Métodos}

O trabalho foi conduzido na Estação Experimental Terras Secas, no município de Pedro Avelino, de propriedade da Empresa de Pesquisa Agropecuária do Rio Grande do Norte S/A(EMPARN). O município está situado na zona semiárida do Estado, com precipitação pluviométrica média anual de 578,9 $\mathrm{mm}$, concentrada nos meses de março e abril. A temperatura média anual é de $27,2^{\circ} \mathrm{C}$ e a umidade relativa média anual de $70 \%$ (Ministério de Minas e Energia, 2005).

Foram utilizadas 84 matrizes e dois reprodutores da raça Canindé. Aproximadamente um mês antes do início do experimento, todos os animais foram vermifugados; daí em diante, as cabras passaram a ser avaliadas mensalmente e tratadas, apenas, aquelas que mostravam grau de anemia em consonância com o descrito para o método FAMACHA ${ }^{\circ}$ (Vieira, 2008). As fêmeas foram submetidas à avaliação do escore de condição corporal (ECC) antes do início da estação de monta (EM) e ao parto, seguindo a escala de escore de um (01) a cinco (05) conforme descrito por Marcílio \& Sousa (2006). Após classificação pelo ECC, as matrizes foram agrupadas três a três e sorteadas, aleatoriamente, para dois tratamentos: T0 e TI com 25 e 59 fêmeas, respectivamente.

Durante o dia as fêmeas foram mantidas na mesma área de pastejo tendo como suporte forrageiro, a vegetação nativa, predominantemente de caatinga. Em torno das 17:00h as matrizes retornavam ao centro de manejo onde eram separadas por tratamento e tinham acesso livre à água e à mistura múltipla com a seguinte composição $(\mathrm{kg})$ : milho em grão triturado, 27,00; farelo de soja, triturado, 15,00; cloreto de sódio, 30,00; caprinofós, 17,00; ureia, 10,00 e flor de enxofre, 1,00 (Barros \& Bomfim, 2004). A suplementação com mistura múltipla na quantidade máxima de $2 \mathrm{~g} \mathrm{~kg}^{-1}$ de peso vivo foi disponibilizada a partir de 24 dias antes do início da estação de monta até o desmame das crias e a EM foi realizada no período de 01.03 a 18.04 .2010 , somando 49 dias de duração.

Os reprodutores tinham livre acesso às matrizes no cabril, no período das 17:00 h às 07:00 $\mathrm{h}$ do dia seguinte, mantendo-se um (01) reprodutor por tratamento. O diagnóstico de gestação por ultrassonografia, foi feito aos 38 dias e aos 65 dias, após o início da EM.

Aproximadamente uma semana antes da data prevista para o parto a cabra permanecia no centro de manejo visando favorecer o acompanhamento e, caso necessário, a assistência à mãe e a(s) cria(s) no transcorrer do periparto. Após o parto a fêmea continuava no centro de manejo com a cria ao pé, por três a cinco dias, quando então voltava a ter acesso à caatinga, enquanto as crias permaneciam no centro de manejo. Imediatamente após a primeira mamada a cria era identificada e pesada e daí em diante, a cada 28 dias, até o desmame, que ocorreu entre 70 e 84 dias de idade. O cordão umbilical foi cortado e o coto imerso uma única vez, em tintura de iodo a $10,0 \%$ por um a dois minutos. A partir do início da segunda semana de vida as crias tinham livre acesso à mistura concentrada à base de milho em grão $(56,0 \%)$ e farelo de soja $(40,0 \%)$ triturados, adicionada de sal mineral com monensina na proporção de $4,0 \%$ e a capim elefante verde, picado, no 
cocho, à vontade. Os dados foram submetidos à ANOVA e as médias comparadas pelo teste de Tukey a 5,0\% de significância.

\section{Resultados e Discussão}

A fertilidade média das fêmeas ao diagnóstico por ultrassonografia e ao parto foi, respectivamente, 94,05\% e $85,71 \%$, não havendo influência de tratamento $(\mathrm{P}>0,05)$ (Tabela 1).

Tabela 1. Fertilidade de matrizes da raça Canindé por ultrassonografia e ao parto

\begin{tabular}{ccccc}
\hline Variável & \multicolumn{2}{c}{ Ultrassonografia } & \multicolumn{2}{c}{ Ao parto } \\
\hline Tratamento & $\mathbf{N}^{\mathbf{1}}$ & $\mathbf{N}^{\mathbf{2}} \mathbf{( \% )}$ & $\mathbf{N}^{\mathbf{1}}$ & $\mathbf{n}(\%)$ \\
\hline T0 & 25 & $25(100,00)$ & 25 & $23(92,00)$ \\
TI & 59 & $54(91,53)$ & 59 & $49(83,10)$ \\
Total & 84 & $79(94,05)$ & 84 & $72(85,71)$ \\
\hline P & \multicolumn{2}{c}{0,1366 NS } & \multicolumn{2}{c}{0,2895 NS } \\
\hline
\end{tabular}

$\mathrm{N}^{1}=$ número de animais; $\mathrm{N}^{2}$ = número de animais férteis à ultrassonografia; $\mathrm{n}=$ número de animais férteis ao parto.

O escore de condição corporal (ECC) das matrizes na préestação de monta influenciou a fertilidade a ultrassonografia $(\mathrm{P}<0,05)$. As fêmeas com ECC de 2,0 a 2,5 (35); 3,0 a 3,5 (44) e $\geq 4,0$ (5) apresentaram fertilidade a ultrassonografia de $91,43 \% ; 97,73 \%$ e $80,00 \%$, respectivamente.

A fertilidade referente às matrizes com maior ECC foi inferior àquelas inerentes às demais $(\mathrm{P}<0,05)$ as quais não diferiram entre si (Tabela 2). Esses resultados estão em consonância com as recomendações de que as matrizes de pequenos ruminantes domésticos com $\mathrm{ECC} \leq \mathrm{a} 1,5 \mathrm{e} \geq$ a 4,0 não devem ser expostas temporariamente a EM (Marcílio \& Sousa, 2006). Em virtude de se encontrarem gordas e aquelas por estarem magras. Ressalte-se que ambas as condições afetam negativamente o comportamento e o desempenho reprodutivo das matrizes.

Independente do tratamento, a fertilidade ao parto foi de $85,71 \%$ enquanto a fertilidade ao parto para T0 e TI foi de $92,00 \%$ e $83,10 \%$, respectivamente $(\mathrm{P}>0,05)$. Esses resultados são condizentes com os descritos para caprinos e ovinos por Alves et al. (2007) e Hamilton et al. (2009). Ressalte-se que, diariamente, a exposição das matrizes aos reprodutores foi de aproximadamente $14 \mathrm{~h}$. Considerando-se as condições climáticas da região Nordeste, o acasalamento por um período mais curto e predominantemente à noite, contribui positivamente para o comportamento e o desempenho das matrizes e dos reprodutores. Afora nas demais 10 horas no transcorrer do dia favorecer o repouso e o consumo de alimentos e, desta forma, minimizar o desgaste físico, em especial dos reprodutores (Castelo et al., 2009; Simplício

Tabela 2. Fertilidade à ultrassonografia de acordo com o escore de condição corporal pré-estação de monta

\begin{tabular}{|c|c|c|}
\hline ECC & $\mathbf{N}$ & $\%$ \\
\hline 2 a 2,5 & 35 & $91,43^{a}$ \\
\hline 3 a 3,5 & 44 & $97,73^{a}$ \\
\hline$\geq 4$ & 5 & $80,00^{b}$ \\
\hline Média & 84 & 94,05 \\
\hline$P$ & \multicolumn{2}{|c|}{0,2017} \\
\hline
\end{tabular}

ECC = escore de condição corporal; $\mathrm{N}=$ número de animais.

Valores seguidos de letras diferentes na mesma coluna, diferem entre si, $P<0,05$.
\& Simplício, 2009). Os resultados levam à reflexão sobre a necessidade e importância de se explorar melhor a proporção reprodutor matrizes majoritariamente recomendada como um (1) para 25, sem se considerar as condições às quais os animais são expostos, em particular o regime de manejo e a experiência sexual dos indivíduos, fêmeas e machos.

$\mathrm{O}$ tipo de nascimento influenciou $(\mathrm{P}<0,05)$ o peso das crias, do nascer ao desmame, aos 84 dias, sendo que aquelas oriundas de nascimento simples foram mais pesadas que as de nascimento múltiplo (Tabela 3).

Tabela 3. Desenvolvimento ponderal de crias Canindé (média $\pm \mathrm{dp}$ ) de acordo com o tipo de nascimento e o sexo

\begin{tabular}{ccccc}
\hline Variável & PN & P28 & P56 & P84 \\
\hline Tipo Nascimento & & & & \\
Simples (28) & $2,09 \pm 0,47^{\mathrm{a}}$ & $4,66 \pm 1,20^{\mathrm{a}}$ & $8,33 \pm 2,74^{\mathrm{a}}$ & $10,41 \pm 3,64^{\mathrm{a}}$ \\
Múltiplo (91) & $1,82 \pm 0,37^{\mathrm{b}}$ & $3,54 \pm 0,68^{\mathrm{b}}$ & $7,25 \pm 1,44^{\mathrm{b}}$ & $9,18 \pm 2,03^{\mathrm{b}}$ \\
\hline Sexo & & & & \\
Macho (55) & $1,95 \pm 0,45$ & $4,11 \pm 1,08^{\mathrm{a}}$ & $7,97 \pm 1,95$ & $10,10 \pm 3,21$ \\
Fêmea (64) & $1,82 \pm 0,36$ & $3,68 \pm 0,89^{\mathrm{b}}$ & $7,27 \pm 1,50$ & $9,15 \pm 2,10$ \\
Total (119) & $1,88 \pm 0,41$ & $3,86 \pm 0,99$ & $7,56 \pm 1,95$ & $9,53 \pm 2,63$ \\
CV, \% & 21,84 & 25,77 & 25,75 & 27,60 \\
\hline
\end{tabular}

PN = peso ao nascer; $\mathrm{P} 28$ = peso aos 28 dias de idade; $\mathrm{P} 56$ = peso aos 56 dias de idade; $\mathrm{P} 84=$ peso aos 84 dias de idade; $C V=$ coeficiente de variação.

Valores seguidos de letras diferentes na mesma coluna para cada variável diferem entre si, $\mathrm{P}<0,05$

Resultados semelhantes foram descritos por Maia \& Costa (1997) e Silva \& Araujo (2000) para crias caprinas nativas, na zona semiárida do Nordeste brasileiro, e Oliveira et al. (2009) para crias da raça Anglo-nubiana, também no Nordeste do Brasil. A diferença de peso entre as crias de nascimento simples e múltiplo, sobretudo, nas primeiras semanas de vida, pode ser atribuída ao consumo de leite e ao peso ao nascer (PN), uma vez que as crias oriundas de nascimento simples tiveram maior PN e, possivelmente, receberam mais leite das mães que aquelas de nascimento múltiplo. No entanto, ressalta-se que a partir da segunda quinzena do segundo mês pós-parto a produção de leite das matrizes nativas começa a declinar (Maia \& Costa, 1997). Daí a importância da oferta de alimentos sólidos, concentrados e volumosos, a partir da segunda semana de vida das crias. Este manejo alimentar certamente favorece o desenvolvimento dos compartimentos gástricos e os animais passam a consumir e digerir os alimentos mais cedo. O que está em consonância com os resultados de Amaral et al. (2007) ao descreverem, em relação ao o consumo de alimentos sólidos, a idade precoce tem efeito benéfico sobre a sobrevivência e o desenvolvimento corporal de crias caprinas no transcorrer do período de amamentação.

$\mathrm{O}$ sexo das crias exerceu efeito significativo $(\mathrm{P}<0,05)$, sobre o peso, apenas aos 28 dias (Tabela 3), contrastando com os resultados de Silva \& Araujo (2000) em crias caprinas de vários genótipos, no Ceará, e de Oliveira et al. (2009) em crias da raça Anglo-nubiana, na Bahia. Esses autores afirmam que entre as crias caprinas os machos são mais pesados do que as fêmeas, em todas as idades avaliadas; no entanto, Maia \& Costa (1997) embora trabalhando com crias da raça Canindé, na zona semiárida do RN, não observaram influência do sexo sobre o desenvolvimento ponderal no período de amamentação.

\section{Conclusões}

A fertilidade ao parto não foi influenciada pelo tratamento mas o escore de condição corporal das matrizes ao início 
da estação de monta, afetou a fertilidade avaliada por ultrassonografia.

A suplementação com mistura múltipla contendo 10,00\% de ureia a partir de 24 dias que antecederam o início da estação de monta, foi compatível com o alcance de fertilidade elevada.

$\mathrm{O}$ tipo de nascimento, preferivelmente ao sexo, influencia o desenvolvimento corporal das crias ao longo de todo o período de amamentação.

\section{Literatura Citada}

Alves, N. G.; Torres, C. A. A.; Rodrigues, M. T.; Cecon, P. R.; Santos, A. D. F.; Siquiera, L. G. B. Bitencourt, L. L.; Moraes, E. A. Efeito do nível de uréia na dieta sobre o desempenho, a qualidade e o estádio de desenvolvimento embrionário em cabras Alpinas. Arquivo Brasileiro de Medicina Veterinária e Zootecnia, v.59, n.4, p.996-1005, 2007. <http://dx.doi. org/10.1590/S0102-09352007000400028>.

Amaral, C. M. C.; Pelicano, E. R. L.; Yanez, E. A.; Souza, H. B. A. de; Machado, M. R. F.; Sugohara, A.; Resende, K. T. de. Características de carcaça e qualidade de carne de cabritos Saanen alimentados com ração completa farelada, peletizada e extrusada. Ciência Rural, v.37, n.2, p.550-556, 2007. $<$ http://dx.doi.org/10.1590/S0103-84782007000200040>.

Barros, N. N.; Bomfim, M. A. D. Mistura múltipla para caprinos e ovinos. In: Seminário Nordestino de Pecuária, 8., 2004, Fortaleza. Anais ... Fortaleza: FAEC, 2004. p.50-67.

Canfield, R. W.; Sniffen, C. J.; Butler, W. R. Effects of excess degradable protein on postpartum reproduction and energy balance in dairy cattle. Journal of Dairy Science, v.73, p.2342-2349, 1990. <http://dx.doi.org/10.3168/jds.S00220302(90)78916-3>.

Castelo, T. S.; Simplicio, A. A.; Silva, A. R.; Barreto, I. M. L. G.; Lira, R. A.; Verissimo, A. M. O. T. Desempenho reprodutivo de fêmeas caprinas nulíparas submetidas à estação de monta em plena época seca do ano. Acta Veterinária Brasílica, v.3, n.1, p.30-32, 2009. <http://periodicos.ufersa.edu.br/revistas/ index.php/acta/article/view/1033>. 15 Jul. 2013.

Elrod, C. C.; Butler, W. R. Reduction of fertility and alteration of uterine $\mathrm{pH}$ in heifers fed excess ruminally degradable protein. Journal of Dairy Science, v.71, n.3, p.694701, 1993. <http://www.journalofanimalscience.org/ content/71/3/694>. 15 Jul. 2013.

Elrod, C. C.; van Amburgh, M.; Butler, W. R. Alterations of $\mathrm{pH}$ in response to increased dietary protein in cattle are unique to the uterus. Journal of Dairy Science, v.71, n.3, p.702-706, 1993. <http://journalofanimalscience.org/ content/71/3/702>. 15 Jul. 2013.

Fahey, J.; Boland, M. P.; O'Callaghan, D. The effects of urea on embryo development in superovulated donor ewes and on early embryo survival and development in recipient ewes. Animal Science, v.72, n.2, p.395-400, 2001.

Hamilton, S. T. R. dos; Lucci, C. S.; Madureira, E. H.; Narimatsu, S.; Goulart, R. H.; Gil, J.; Fontolan, V.; Baruselli, M. S. Características seminais de ovinos suplementados ou não com uréia e diferentes fontes de enxofre. Brazilian Journal of Veterinary Research and Animal Science, v.46, n.1, p.54-61, 2009. <http://www.revistas.usp.br/bjvras/article/ view/26750/28533>. 15 Jul. 2013.
Jordan, E. R.; Swanson, L. V. Effect of crude protein on reproductive efficiency, serum total protein, and albumin in the high-producing dairy cows. Journal of Dairy Science, v.62, n.1, p.58-63, 1979. <http://dx.doi.org/10.3168/jds. S0022-0302(79)83202-6>.

Maia, M.; Costa, A. N. Avaliação do desempenho reprodutivo de um rebanho de cabras da raça Canindé, na zona semi-árida do Rio Grande do Norte. Revista Brasileira de Zootecnia, v.26, n.1, p.46-53, 1997. <http://www. revista.sbz.org.br/artigo/visualizar.php? artigo $=8>. \quad 15$ Jul. 2013.

Marcilio, F. C.; Sousa, W. H. Avaliação e utilização da condição corporal como ferramenta de melhoria da reprodução e produção de ovinos e caprinos de corte. In: Reunião Anual da Sociedade Brasileira de Zootecnia, 43., 2006, João Pessoa. Anais... João Pessoa: SBZ, 2006, p.649-678.

McEvoy, T. G.; Robinson, J. J.; Aitken, R. P.; Findlay, P. A.; Robertson, I. S. Dietary excesses of urea influence the viability and metabolism of preimplantation sheep embryos and may affect fetal growth among survivors. Animal Reproduction Science, v.47, n.1-2, p.71-90, 1997. <http:// dx.doi.org/10.1016/S0378-4320(96)01627-2>.

Medeiros, L. F. D.; Vieira, D. H.; Luna, M. C. M. de; Cabral Neto, O. Desempenho de um rebanho caprino Anglonubiano, no Município do Rio de Janeiro. II - Fatores que afetam o peso ao nascer e a mortalidade. Boletim da Indústria Animal, v.63, n.2, p.71-81, 2006. <http://www. iz.sp.gov.br/pdfsbia/1180007791.pdf>. 22 Jul. 2013.

Mellado, M.; Cantú, L.; Suárez, J. E. Effects of body condition, length of breeding period, buck:doe ratio, and month of breeding on kidding rates in goats under extensive conditions in arid zones of Mexico. Small Ruminant Research, v.23, n.1, p.29-35, 1996. <http://dx.doi. org/10.1016/S0921-4488(96)00896-6>.

Mellado, M.; Vera, A.; Loera, H. Reproductive performance of crossbred goats in good or poor body condition exposed to bucks before breeding. Small Ruminant Research, v.14, n.1, p.45-48, 1994. <http://dx.doi.org/10.1016/09214488(94)90008-6>.

Ministério de Minas e Energia. Projeto cadastro de fontes de abastecimento por água subterrânea estado do Rio Grande do Norte: Diagnóstico do município de Pedro Avelino. Recife: MME, 2005. 11p.

Oliveira, D. F.; Cruz, J. F.; Carneiro, P. L. S.; Malhado, C. H. M.; Rondina, D.; Ferraz, R. C. N.; Teixeira Neto, M. R. Desenvolvimento ponderal e características de crescimento de caprinos da raça Anglonubiana criados em sistema semi-intensivo. Revista Brasileira de Saúde e Produção Animal, v.10, n.2, p.256-265, 2009. <http:// revistas.ufba.br/index.php/rbspa/article/view/1707/821>. 05 Ago. 2013.

Papadopoulos, S.; Lonergan, P.; Gath, V.; Quinn, K. M.; Evans, A. C.; O'Callaghan, D.; Bolan, M. P. Effect of diet quantity and urea supplementation on oocyte and embryo quality in sheep. Theriogenology, v.55, n.5, p.1059-1069, 2001. <http://dx.doi.org/10.1016/S0093691X(01)00466-6>. 
Sarmento, J. L. R.; Pimenta Filho, E. C.; Abreu, U. G. P. de; Ribeiro, M. N.; Sousa, J. E. R. de. Prolificidade de caprinos mestiços leiteiros no semiárido nordestino. Revista Brasilera de Zootecnia, v.39, n.7, p.14711476, 2010. <http://dx.doi.org/10.1590/S1516$35982010000700011>$.

Silva, F.L.R.;Araújo,A.M. Desempenhoprodutivo em caprinos mestiços no semi-árido do Nordeste do Brasil. Revista Brasileira de Zootecnia, v.29, n.4, p.1028-1035, 2000. $<$ http://dx.doi.org/10.1590/S1516-35982000000400012>.

Simplício, A. A.; Simplício, K. M. M. G. Caprino-ovinocultura de corte: manejo reprodutivo e sua importância para o sucesso da exploração. In: Ximenes, L. J. F.; Martins, G. A.; Narciso Sobrinho, J.; Carvalho, J. M. M. de (Orgs.). As ações do Banco do Nordeste do Brasil em P \& D na arte da pecuária de caprinos e ovinos no Nordeste Brasileiro. Fortaleza: Banco do Nordeste do Brasil, 2009. Cap.7, p.201-250. (Série BNB Ciência e Tecnologia, n.3).
Simplício, A. A.; Ximenes, L. J. F. O Manejo reprodutivo como ferramenta para o aumento da oferta de carnes caprina e ovina. In: Ximenes, L. J. F.; Martins, G. A.; Morais, O. R. de; Costa, S. de A.; Nascimento, J. L. S. do (Orgs.). Ciência e tecnologia na pecuária de caprinos e ovinos. Fortaleza, Banco do Nordeste do Brasil, 2010. Cap. 22, p.524-557. (Série BNB Ciência e Tecnologia, n.5).

Soares Filho, G.; McManus, C.; Mariante, A. S. Fatores genéticos e ambientais que influenciam algumas características de reprodução e produção de leite em cabras no Distrito Federal. Revista Brasileira de Zootecnia, v.30, n.1, p.133-140, 2001. <http://dx.doi.org/10.1590/S1516$35982001000100020>$.

Vieira, L. da S. Métodos alternativos de controle de nematóides gastrintestinais em caprinos e ovinos. Tecnologia \& Ciência Agropecuárias, v.2, n.2, p.49-56, 2008. <http:// www.emepa.org.br/revista/volumes/tca_v2_n2_jun/tca09 metodos.pdf>. 02 Ago. 2013. 